\title{
Pituitary dysfunction following traumatic brain injury: clinical perspectives
}

This article was published in the following Dove Press journal:

Neuropsychiatric Disease and Treatment

27 July 2015

Number of times this article has been viewed

\section{Fatih Tanriverdi \\ Fahrettin Kelestimur \\ Department of Endocrinology, Erciyes University Medical School, Kayseri, Turkey}

Correspondence: Fatih Tanriverdi Department of Endocrinology, Erciyes University Medical School, Kayseri 38039, Turkey

Tel +90352 2076666 ext 21914

Fax +903524375807

Email fatihtan@erciyes.edu.tr
Abstract: Traumatic brain injury (TBI) is a well recognized public health problem worldwide. TBI has previously been considered as a rare cause of hypopituitarism, but an increased prevalence of neuroendocrine dysfunction in patients with TBI has been reported during the last 15 years in most of the retrospective and prospective studies. Based on data in the current literature, approximately $15 \%-20 \%$ of TBI patients develop chronic hypopituitarism, which clearly suggests that TBI-induced hypopituitarism is frequent in contrast with previous assumptions. This review summarizes the current data on TBI-induced hypopituitarism and briefly discusses some clinical perspectives on post-traumatic anterior pituitary hormone deficiency.

Keywords: traumatic brain injury, hypopituitarism, head trauma, pituitary, growth hormone deficiency

\section{Introduction}

Traumatic brain injury (TBI) could be defined as a change in brain function or other evidence of brain pathology caused by external forces, ${ }^{1}$ and is a well recognized public health problem worldwide. A substantial number of people with TBI are seen in emergency departments; the great majority, approximately 235,000 each year, are hospitalized because of non-fatal TBI and nearly 50,000 die according to reports from the USA. Further, the overall annual incidence of TBI in the USA has been reported to be 506 per 100,000 population. ${ }^{2}$ The severity ratio of hospitalized TBI patients was reported to be approximately $22: 1.5: 1$ for mild to moderate to severe cases, respectively. ${ }^{3}$ Thus, there is no doubt that TBI is one of the most common causes of mortality and long-term disability among young adults. The main causes of TBI are road traffic accidents (the leading cause, accounting for $50 \%$ of all cases), falls, violence-related incidents, sports-related head trauma (hockey, soccer, football), combative sports (boxing and kickboxing) characterized by chronic repetitive head trauma, and war-related accidents, including blast injuries. ${ }^{4-7}$

Although TBI has previously been considered as a rare cause of hypopituitarism, an increased prevalence of neuroendocrine dysfunction in patients with TBI has been reported during the last 15 years in most of the retrospective and prospective studies. ${ }^{8-18}$ This review summarizes the current data on TBI-induced hypopituitarism and briefly discusses some clinical perspectives on post-traumatic anterior pituitary hormone deficiency.

\section{Frequency of TBI-induced chronic hypopituitarism}

TBI-induced hypopituitarism was first reported approximately 95 years ago. ${ }^{19}$ Until recently, neuroendocrine dysfunction after TBI was thought to be an uncommon disorder, with only approximately 367 cases of TBI-induced hypopituitarism reported before $2000 .^{10}$ 
However, two cornerstone papers published in 2000 drew attention to TBI-induced pituitary dysfunction and stimulated new research. ${ }^{10,12}$ Although the frequency of chronic hypopituitarism (generally accepted as lasting at least 3 months) after TBI varies widely between the studies, most report a range of $15 \%-50 \%{ }^{9,15-17}$ The frequency of pituitary dysfunction varies according to the severity of trauma, type of trauma, time elapsed since trauma, study population, study design, endocrine testing, and the criteria used to diagnose anterior pituitary hormone deficiency. ${ }^{20}$ The Glasgow Coma Scale (GCS) is the clinical tool most commonly used to evaluate the severity of head trauma. It assesses eye opening and verbal and motor responses on a scale ranging from 3 to 15. The severity of brain injury is graded as mild (GCS 13-15), moderate (GCS 9-12), or severe (GCS 3-8). ${ }^{21}$

In a meta-analysis by Schneider et al that included 1,015 TBI patients from ten cross-sectional and four prospective studies, the pooled prevalence of anterior hypopituitarism has been reported as $27.5 \%$ (95\% confidence interval 22.8-28.9). The most common pituitary hormone deficiencies found in the majority of the studies were growth hormone and gonadotropin (follicle-stimulating hormone/luteinizing hormone $[\mathrm{FSH} / \mathrm{LH}])$ deficiencies. The pooled prevalence of hypopituitarism in mild, moderate, and severe TBI was estimated to be $16.8 \%, 10.9 \%$, and $35.3 \%$, respectively. These data clearly show that although the risk of developing hypopituitarism is highest in patients with severe TBI, the risk is substantially high in mild TBI even comparable with moderate TBI. However, it is important to mention that all patients with mild TBI included in the meta-analysis needed hospitalization and neurosurgical intervention. ${ }^{22}$ In a recent retrospective screening study that included 340 patients with TBI, $28.5 \%$ showed pituitary hormone dysfunction in at least one axis and $4.5 \%$ in two or more axes. Gonadotropin (40.7\%), adrenocorticotropic hormone (ACTH; 23.7\%), and growth hormone (20.7\%) deficiencies were found to be the most common pituitary hormone disturbances. ${ }^{23}$ In a recent systematic review of 27 studies (including 2,117 TBI patients) that evaluated all pituitary axes, 31\% (95\% confidence interval 23-40) of the patients had long-term (>12 months) hypopituitarism, as defined by at least one anterior pituitary hormone deficiency. ${ }^{24}$ In contrast, in one study, hypopituitarism was reported to be rare $(<1 \%$ at a median 13 months after TBI) in unselected head trauma patients admitted to emergency departments, and it was concluded that routine pituitary screening in these patients is unlikely to be cost-effective. However, most of the patients in that study had mild TBI and do not need hospitalization and/or neurosurgical intervention, and most were discharged directly from the emergency service. ${ }^{25}$ It is tempting to speculate that when the extremely high number of people suffering TBI is taken into account, even low rates of hypopituitarism, such as $1 \%$, translate into a large number of patients with TBI-induced pituitary dysfunction. There is an insufficient number of prospective studies in the literature. Only three, long-term, prospective studies have evaluated pituitary function for longer than 12 months. ${ }^{17,18,26}$ In the study by Kleindienst et al, 23 patients with mild, moderate, or severe TBI were screened during the acute phase and at 24-36 months after their injury. In the chronic phase, 48\% of the patients had ACTH deficiency and 39\% had growth hormone deficiency. ${ }^{26}$ In the 3-year prospective study of 30 patients ( $63 \%$ with mild TBI) by Tanriverdi et al $23.3 \%$ had growth hormone deficiency and 6.6\% had ACTH deficiency 3 years after TBI. ${ }^{17}$ The longest prospective study, performed by the same research group, evaluated 25 patients (64\% with mild TBI and 36\% with moderate or severe TBI) 1,3 , and 5 years after TBI. Although most of the pituitary hormone deficiencies improved over time, there were significant rates of pituitary hormone deficiency 5 years after TBI (28\% growth hormone, $4 \% \mathrm{ACTH}$, and 4\% gonadotropin). ${ }^{18}$ The main limitation of these prospective studies was the low numbers of patients screened.

In summary, according to the current literature, approximately $15 \%-20 \%$ of TBI patients may develop chronic hypopituitarism, which clearly suggests that TBI-induced hypopituitarism is a frequent problem, in contrast with previous assumptions. However, there are no epidemiological studies showing the burden of the disease in the population. Post-traumatic hypopituitarism is generally characterized by isolated anterior pituitary hormone deficiency rather than multiple hormone deficiencies, and growth hormone deficiency seems to be the most common disorder.

\section{Screening strategies during acute and chronic phases of TBI Which patients should be screened?}

Because TBI is an important cause of hypopituitarism, the first approach could involve testing all patients with a history of TBI. However, this strategy is not cost-effective and would result in unnecessary consumption of health care resources in the community. Therefore, the most important clinical challenge is to determine which TBI patients should be screened for pituitary dysfunction.

The first consensus guideline on screening for hypopituitarism following TBI was published by Ghigo et al in 2005. 
All TBI patients who need hospitalization in neurosurgery units or intensive care units, regardless of severity, should be screening for pituitary function in the acute phase, and prospective evaluations for 12 months are recommended in this guideline. Further, the authors suggest that, for retrospective evaluation at any time after surgery, all patients who experience moderate or severe injury and who have clinical signs and/or symptoms associated with hypopituitarism should be screened for pituitary function. ${ }^{27}$ While this guideline has filled an important gap in the field of posttraumatic hypopituitarism, it drew on only three 12-month prospective studies, and the data regarding mild TBI were only preliminary. In addition, some experts in the field suggest that global screening for hypopituitarism would only be to focus on patients with moderate or severe head trauma $(\mathrm{GCS}<13)$ from a practical point of view. ${ }^{28-32}$ This approach seems to be logical and practical because the severity of head trauma is a strong predictor. ${ }^{24}$ However, in a meta-analysis including 1,015 TBI patients, the pooled prevalences of hypopituitarism in mild, moderate, and severe TBI were estimated as $16.8 \%, 10.9 \%$, and $35.3 \%$, respectively. Based on these findings, Schneider et al recommend that all patients hospitalized for TBI should be considered for endocrine evaluation. ${ }^{22}$ These data clearly show that although the risk of developing hypopituitarism is highest in severe TBI, the risk is substantially high in mild TBI and is even comparable with moderate TBI. Moreover, when we consider the high frequency of mild TBI among all TBI patients, it is obvious that pituitary dysfunction is not uncommon in patients with mild TBI and cannot be ignored. It is important to note that most of the mild TBI patients included in this meta-analysis and in the previous studies had complicated mild TBI, ${ }^{16-18,22}$ as outlined later in this paper.
Although mild TBI is the most common type of head trauma, global screening of all mild TBI patients is not practical or cost-effective. ${ }^{33}$ Therefore, selecting mild TBI patients who have a significant risk for pituitary dysfunction is a strategic clinical challenge. It is important to recognize that, by definition, mild TBI is a heterogeneous diagnosis, and selection bias in TBI research is a major problem in this patient group. ${ }^{34}$ Some mild TBI patients may not have loss of consciousness and could be accepted as suffering from minor head trauma; on the other hand, some mild TBI patients may need monitoring in intensive care and neurosurgical intervention. It is documented that approximately $40 \%$ of mild TBI patients do not experience loss of consciousness. ${ }^{35}$ However, previous studies have shown that approximately 10\%-39\% of patients with mild TBI have intracranial abnormalities (eg, hematoma, edema, or contusion) detected on computed tomography (CT) on the day of injury. ${ }^{36-38}$ Williams et al used the term "complicated mild TBI", as defined by the presence of skull fractures or intracranial abnormalities on initial CT. ${ }^{39}$ It was clearly demonstrated that neuropsychological functioning in complicated mild TBI is significantly poorer than in uncomplicated TBI. ${ }^{40}$ Although there is no study comparing the risk of hypopituitarism between patients with "complicated mild TBI" versus "uncomplicated mild TBI", most mild TBI patients screened for hypopituitarism in the literature have at least one of the features of complicated TBI (Figure 1). For example, in one 3-year, prospective, follow-up study, $63 \%$ of patients had mild TBI and three of $18(17 \%)$ mild TBI patients had pituitary dysfunction. All mild TBI patients included in the study needed hospitalization for more than 24 hours, and the majority of these patients were monitored in intensive care. Moreover, 15 of 18 patients with mild TBI (including three patients with hypopituitarism) had

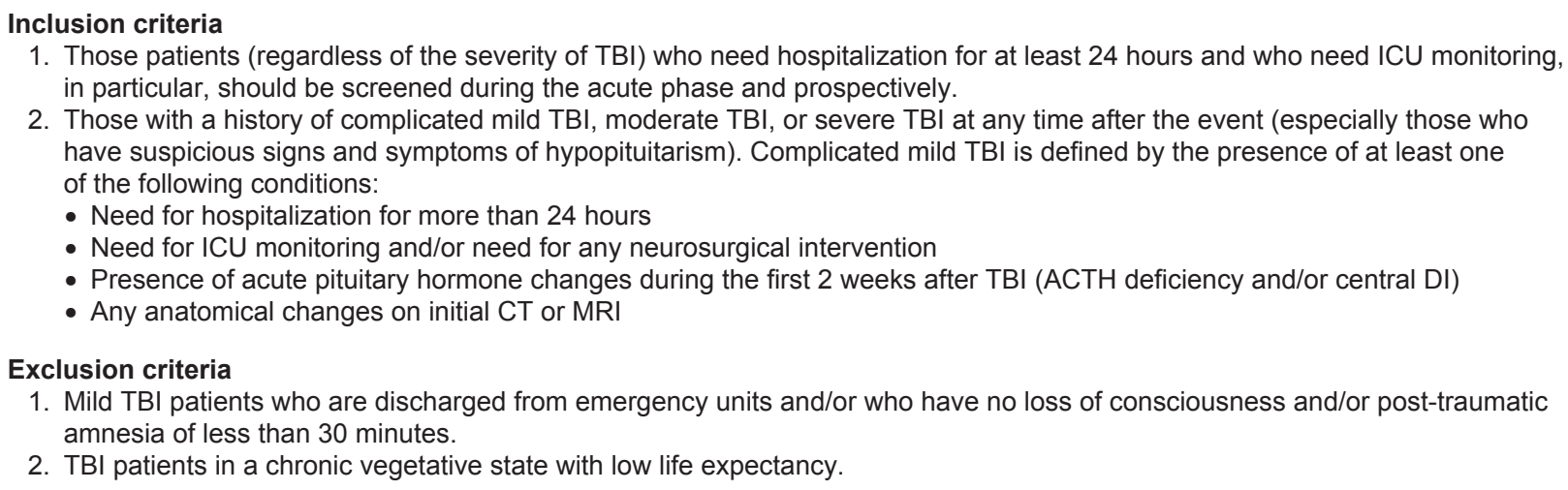

2. Those with a history of complicated mild TBI, moderate TBI, or severe TBI at any time after the event (especially those who have suspicious signs and symptoms of hypopituitarism). Complicated mild TBI is defined by the presence of at least one of the following conditions:

- Need for hospitalization for more than 24 hours

- Need for ICU monitoring and/or need for any neurosurgical intervention

- Presence of acute pituitary hormone changes during the first 2 weeks after TBI (ACTH deficiency and/or central DI)

- Any anatomical changes on initial CT or MRI

Exclusion criteria

1. Mild TBI patients who are discharged from emergency units and/or who have no loss of consciousness and/or post-traumatic amnesia of less than 30 minutes.

2. TBI patients in a chronic vegetative state with low life expectancy.

Figure I Suggested inclusion and exclusion criteria for screening of hypopituitarism in patients with mild, moderate, or severe TBI.

Abbreviations: ACTH, adrenocorticotropic hormone; CT, computed tomography; DI, diabetes insipidus; ICU, intensive care unit; MRI, magnetic resonance imaging; $\mathrm{TBI}$, traumatic brain injury. 
an abnormal initial CT (mainly epidural/subhematoma and cranial vault fractures), indicating that patients with complicated mild TBI have a substantial risk of hypopituitarism. ${ }^{17}$ In contrast, it has been reported that hypopituitarism is rare in unselected patients with head trauma admitted to emergency departments. Most of the patients in this study had mild TBI $(\mathrm{n}=77,72 \%)$. Among the mild TBI patients, 53\% did not have loss of consciousness and $90 \%$ had post-traumatic amnesia of less than 30 minutes. Half of the patients with mild TBI were discharged directly from the emergency service without hospitalization; only $14 \%$ of these mild TBI patients needed monitoring in intensive care and none had any neurosurgical intervention. ${ }^{25}$ This study, which mainly included patients with uncomplicated mild TBI, suggests that global pituitary screening of all TBI patients admitted to emergency services is not necessary due to the low risk of hypopituitarism.

Therefore, based on data in the literature and current predictive factors for TBI-induced hypopituitarism, we redefined complicated mild TBI (Figure 1) and recommend routine screening in patients with complicated mild TBI in addition to moderate and severe TBI patients. As an exclusion criterion for pituitary screening, we recommend that mild TBI patients who are discharged from the emergency service with no loss of consciousness and/or post-traumatic amnesia of less than 30 minutes do not need pituitary screening. When we only screen complicated mild TBI patients and use exclusion criteria, more than $50 \%$ of these patients will not be screened unnecessarily. The suggested inclusion and exclusion criteria for screening of hypopituitarism in TBI patients are summarized in Figure 1.

\section{Screening strategy during acute phase of TBI}

The acute phase is generally accepted to be the first 10-14 days after TBI. Evaluation of pituitary function in the acute phase can be difficulty in critically ill TBI patients. Diagnosing and differentiating the hormonal changes as either an adaptive response or as a pathological hormonal deficit is one of the major problems. ${ }^{41,42}$ Performing dynamic hormone tests (in particular for ACTH and growth hormone deficiencies) in the acute phase is either impractical or inappropriate. Moreover, there are no clear or internationally accepted diagnostic cut-off values for diagnosis of hypopituitarism during the acute phase.

Prospective studies evaluating pituitary function have demonstrated that most pituitary hormonal changes (particularly FSH/LH, growth hormone, and thyroid-stimulating hormone [TSH] deficiencies) are transient and recover within 3-12 months of injury. ${ }^{16,26,43-45}$ Currently, there is no clear evidence that replacement of $\mathrm{TSH}, \mathrm{FSH} / \mathrm{LH}$, or growth hormone deficiency in critically ill TBI patients is beneficial during the acute phase. ${ }^{22,32,41}$ However, in the acute phase of TBI, diagnosis of glucocorticoid deficiency should not be missed because it is life-threatening. . $2,46-49$ The current evidence implies that insufficiency in the hypothalamic-pituitaryadrenal axis during the acute phase after head trauma is associated with a worse neurological outcome, increased need for vasoactive drug therapy due to hemodynamic instability, relative or absolute hypoglycemia, hyponatremia, and rapidly progressive hypotension, all of which may increase the risk of morbidity and mortality. ${ }^{46,48,50,51}$ Therefore, the emphasis during the acute phase of brain injury should be on detecting adrenal insufficiency.

To date, there have been only eleven studies evaluating pituitary function in the first 2 weeks after TBI (including mild, moderate, and severe TBI, and mainly screened in intensive care); these have showed the frequency of ACTH deficiency to be between $4 \%$ and $78 \%{ }^{16,26,42,44-46,48,50-53}$ The wide range in the reported percentages between various studies could be due to measurement of morning serum cortisol levels at different time points after head trauma or using different diagnostic cut-off levels for ACTH deficiency. In a recent and elegant study, plasma cortisol levels were measured sequentially on days 1, 3, 5, 7, and 10 in 100 consecutive patients with TBI. A morning plasma cortisol level $\leq 11 \mu \mathrm{g} / \mathrm{dL}(300 \mathrm{nmol} / \mathrm{L})$ was accepted as adrenal insufficiency. During the first 10 days after TBI, 78 of the 100 patients had at least one plasma cortisol measurement $<300 \mathrm{~nm} / \mathrm{L}$, and most of the patients (63 of 78) had glucocorticoid deficiency on days 1,2, and 3. One of the most important findings of this study was the low plasma cortisol has been reported to be significantly associated with increased mortality and existence of hyponatremia. ${ }^{48}$

In summary, all TBI patients (regardless of severity) who need intensive care monitoring should be screened during the acute phase and in a prospective manner (Figure 1). Based on data in the current literature, we recommend assessing only ACTH deficiency by measuring morning basal cortisol levels during the acute phase. We recommend routine cortisol measurement on days 1-4 after TBI and on days 5-10 in the event of clinical suspicion (presence of hyponatremia, hypotension, or need for higher doses of vasopressors, hypoglycemia), and we suggest a morning plasma cortisol level $\leq 11 \mu \mathrm{g} / \mathrm{dL}$ (300 nmol/L) as the diagnostic cut-off for ACTH deficiency during the acute phase. Stress dose glucocorticoid replacement is warranted in critically ill TBI patients who have ACTH deficiency. ${ }^{41,47}$ When the patient is stable and the critically ill phase is resolved (at least 2 weeks after TBI), if the basal 
cortisol level is between $3.5 \mu \mathrm{g} / \mathrm{dL}(98 \mathrm{nmol} / \mathrm{L})$ and $18 \mu \mathrm{g} / \mathrm{dL}$ (500 nmol/L) and clinical findings suggest ACTH deficiency, an appropriate dynamic test needs to be performed before discharge. ${ }^{54}$ In addition, TSH deficiency could be evaluated by measuring basal free T4 and TSH levels when the patient is stable before discharge. Physiological doses of steroid and/or thyroid replacement therapy are recommended in patients with ACTH and/or TSH deficiency until the second reassessment at 6 months after TBI (Figure 2).

\section{Screening strategy during chronic phase of TBI}

Understanding the natural history of TBI-induced hypopituitarism with the long-term prospective studies is critically important to develop an evidence-based screening strategy. Nevertheless, there are still inadequate numbers of long-term prospective studies in the literature. Therefore, our screening recommendations after 12 months (Figure 2) are not strong enough and need to be confirmed by further long-term prospective studies.

So far, six major prospective studies (five including patients with mild, moderate, or severe TBI) investigating pituitary function during the and 12 months later have been published. ${ }^{9,15,16,43-45}$ These prospective studies demonstrated the dynamic characteristics of hypopituitarism in isolated and multiple pituitary deficiencies as well as in the improvement (recovery) or worsening (new onset hormonal deficiencies) of pituitary function. In all six studies, pituitary function recovered over a 12-month period, but in four ${ }^{9,15,16,45}$ newonset pituitary hormone deficiencies (reported as lower

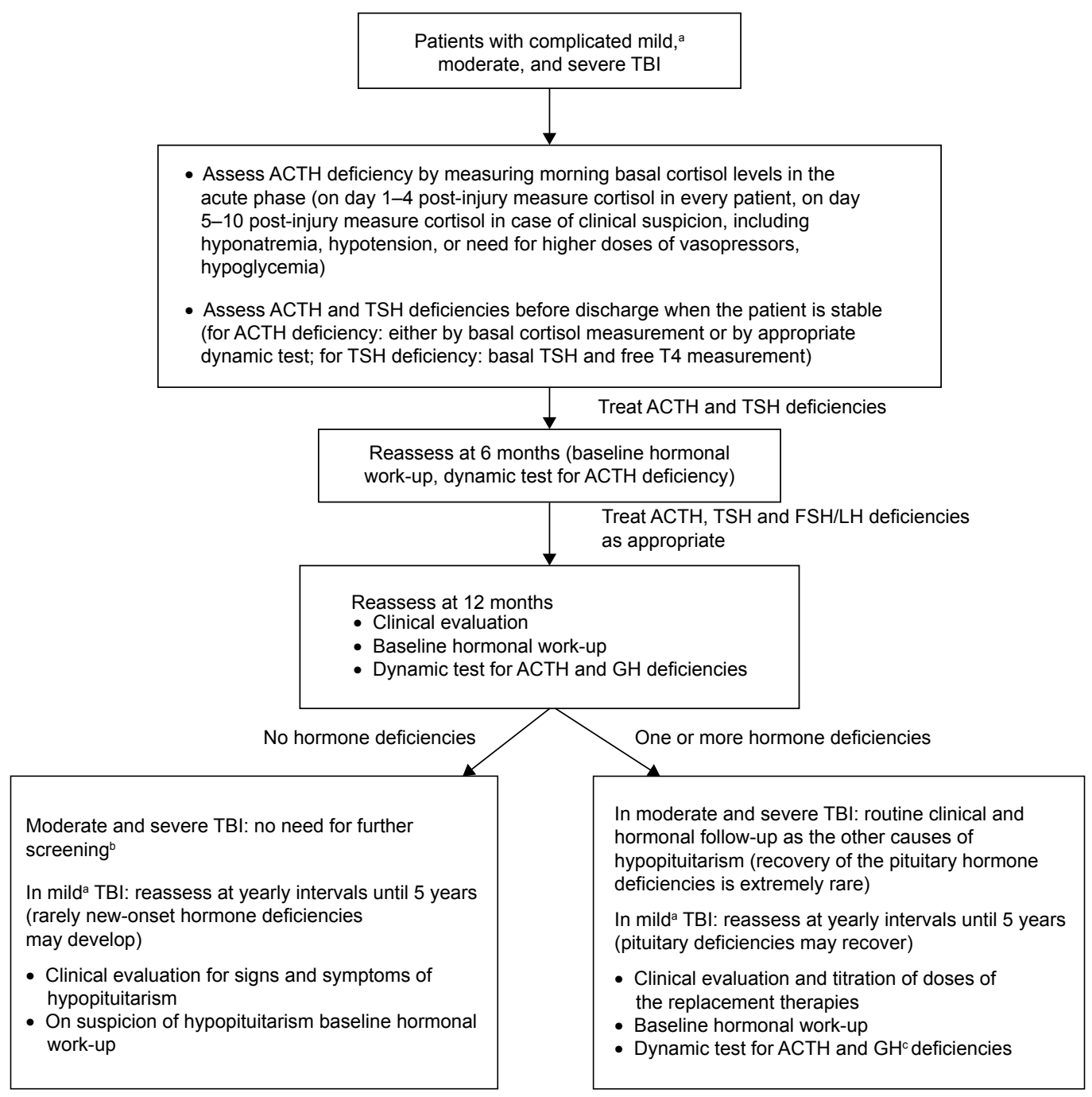

Figure 2 Prospective screening strategy for anterior pituitary function after head trauma in patients with traumatic brain injury.

Notes: a Complicated mild TBI is defined by the presence of at least one of the following conditions: need for hospitalization for more than 24 hours; need for ICU monitoring and/or need for any neurosurgical intervention; presence of acute pituitary hormone changes at the first 2 weeks after TBI (ACTH deficiency and/or central DI); any anatomical changes on initial CT or MRI. 'Patients should be reminded regarding the symptoms and signs of hypopituitarism, and could be re-evaluated when necessary. ${ }^{\mathrm{c}} \mathrm{Dynamic}$ tests for GH deficiency need to be done with an "intent to treat" approach and according to clinical context throughout the follow-up period.

Abbreviations: ACTH, adrenocorticotropic hormone; CT, computed tomography; FSH, follicle-stimulating hormone; GH, growth hormone; ICU, intensive care unit; $\mathrm{LH}$, luteinizing hormone; MRI, magnetic resonance imaging; TBI, traumatic brain injury; TSH, thyroid-stimulating hormone. 
frequency than recovery) were reported at the 12-month evaluation. At the end of 12 months, there were still substantial rates of pituitary hormone deficiencies, ranging from $13 \%$ to $50 \%$, of which growth hormone deficiency was the most common hormonal deficit. The dynamic hormonal changes were defined mainly in the first 6 months but could be seen after 6 months. ${ }^{9,15,16,43-45}$ Consequently, we recommend re-evaluation 6 months after the injury in patients with complicated mild TBI and in those with moderate/ severe TBI (Figure 2), because a 3-month evaluation seems to be too short to give a definite diagnosis due to the high frequency of dynamic hormonal changes. ${ }^{55}$ At the 6-month evaluation, we recommend a baseline hormonal work-up and dynamic testing for ACTH deficiency in patients with mild or moderate/severe TBI. If TSH, FSH/LH, and ACTH deficiencies are present, they should be treated appropriately until the following reassessment at 6 months after TBI. Regarding growth hormone deficiency, we do not suggest dynamic hormonal testing at the 6-month evaluation and we do not recommend growth hormone replacement before the first year of $\mathrm{TBI}^{33,55}$ (Figure 2). This is because isolated growth hormone deficiency has been reported in most of the prospective studies and a significant number of the patients were recovered at 12 months after TBI, and currently there is no clear evidence that early growth hormone replacement could be beneficial for recovery of pituitary function or for rehabilitation of TBI.

Only three long-term prospective studies screening pituitary functions for longer than 12 months have been published. ${ }^{17,18,26}$ In the study by Kleindienst et al, 23 patients with mild, moderate, or severe TBI were screened during the acute phase and at 24-36 months after injury. All the patients with FSH/LH and TSH deficiencies recovered completely at the chronic phase. By the chronic phase, $48 \%$ of the patients had ACTH deficiency and 39\% had growth hormone deficiency. In both the ACTH and growth hormone axes, a significant rate of dynamic hormonal changes (recovery and new-onset deficiencies) have been reported. ${ }^{26}$ Thirty patients were included in the 3-year prospective study, and $63 \%$ had complicated mild TBI and the remaining had moderate or severe TBI. Overall, the proportion of patients with growth hormone deficiency decreased from $43.3 \%$ at 1 year to $23.3 \%$ at 3 years, and the proportion of patients with ACTH deficiency decreased from $20.0 \%$ to $6.6 \%$. No patient had TSH or gonadotropin deficiency after 3 years, compared with $6.6 \%$ and $3.3 \%$, respectively, at 1 year. It is important to note that dynamic hormonal changes were reported mainly in patients with complicated mild TBI, while ACTH and growth hormone deficiencies persisted in patients with severe TBI at the 3-year evaluation. ${ }^{17}$ In the longest prospective study, 25 patients $(64 \%$ with complicated mild TBI and $36 \%$ with moderate or severe TBI) were evaluated at years 1, 3, and 5 after TBI. ACTH and growth hormone deficiencies improved over time in a considerable number of patients with mild or moderate TBI, but in rare instances worsened over the 5-year period. However, in patients with severe TBI, ACTH and growth hormone status at 1 year persisted at 5 years. Thus, the authors recommended that screening pituitary function for 5 after TBI years is important, especially in patients with mild TBI. ${ }^{18}$ The main limitation of these three long-term studies ${ }^{17,18,26}$ is the small numbers of patients, especially in the moderate and severe TBI groups. Further, in the 3-year and 5-year TBI studies, dynamic hormonal changes in patients with moderate TBI were comparable with those in patients with mild or severe TBI. However, based on the strong evidence from retrospective studies, the clinical behavior and neurological and neuroendocrine consequences of moderate TBI are similar to those of severe TBI, and are generally classified with severe TBI. ${ }^{22,27,32}$ Another limitation of the long-term prospective studies is that the number of patients with TSH and gonadotropin deficiencies was not sufficient to improve our understanding of the natural history of these axes. . $^{17,18,26}$

Therefore, based on data in the literature, we have defined inclusion/exclusion criteria (Figure 1) for patient selection, ${ }^{56}$ and recommend prospective screening in patients with moderate or severe TBI and in those with complicated mild TBI. Our suggestions for prospective screening strategies for anterior pituitary function after head trauma in patients with complicated mild TBI and those with moderate/severe TBI are summarized in Figure 2. After the acute and 6-month assessments, we suggest detailed clinical and hormonal evaluation at month 12 after TBI (Figure 2).

In patients with complicated mild TBI, if there is any pituitary hormonal deficiency at month 12 , we recommend appropriate replacement of the deficient hormones. Because of the probability of recovery, yearly clinical and hormonal assessment for at least 5 years is a reasonable approach. During follow-up controls (Figure 2), clinical evaluation, baseline hormonal work-up, and if necessary, dynamic tests for ACTH and growth hormone deficiencies could be performed. If there is no hormonal deficiency at the 12-month assessment in patients with complicated mild TBI, we suggest yearly clinical follow-up for at least 5 years due to the probability of new-onset pituitary hormone deficiencies (Figure 2). It is important to emphasize that hormonal investigations after the 12-month evaluation, particularly dynamic 
tests for growth hormone deficiency, need to be done with an "intent-to-treat" approach and according to the clinical context throughout the follow-up period. . $2,30,33,55^{2}$

In patients with moderate or severe TBI (Figure 2), if there is any pituitary hormonal deficiency at 12 months, we suggest appropriate replacement of the deficient hormones, and because recovery of pituitary dysfunction is extremely rare, we recommend routine follow-up for titration of replacement therapy. If there is no pituitary hormone deficiency at 12 months in patients with moderate or severe TBI, we recommend no further investigation. However, it is essential to inform these patients regarding the symptoms and signs of hypopituitarism, and if they have signs and symptoms suspicious for hypopituitarism, they can be screened at any time after TBI (Figure 2).

\section{Conclusion and future directions}

Patients who developed hypopituitarism after TBI present with the same manifestations as those with hypopituitarism attributable to other causes. The clinical picture depends on the severity of hypopituitarism and the number of deficient anterior pituitary hormones. Patients with hypopituitarism, independent of the etiology, require replacement of deficient hormones as part of their standard clinical care. The diagnosis and treatment of hypopituitarism are beyond the scope of this review, and the details have been reviewed elsewhere. ${ }^{22,56,57}$ However, it is important to note that the clinical manifestations of hypopituitarism, especially isolated hormone deficiencies as in TBI, could be mild or subtle, so most patients with hypopituitarism are likely to remain undiagnosed and thereby untreated. Clinical suspicion, knowledge of risk factors and screening of TBI patients has a critical role in the diagnosis of hypopituitarism.

In conclusion, data in the current literature demonstrate that approximately $15 \%-20 \%$ of patients with TBI develop chronic hypopituitarism, which clearly suggests that, in contrast with previous assumptions, TBI-induced hypopituitarism is a frequent problem. All patients with complicated mild, moderate, or severe TBI need to be screened for hypopituitarism. However, more long-term prospective studies in larger numbers of patients need to be done to develop an evidence-based screening strategy. The pathogenesis of TBIinduced hypopituitarism is still unknown and further studies are warranted to understand the underlying mechanisms. Knowing the pathogenesis and molecular mechanisms could be important to prevent development of pituitary dysfunction after TBI. Nevertheless, it is important to emphasize that growth hormone replacement therapy early after TBI could be beneficial in aiding rehabilitation of TBI patients, but currently no studies have been performed in this area.

\section{Disclosure}

The authors report no conflicts of interest in this work.

\section{References}

1. Menon DK, Schwab K, Wright DW, Maas AI. Position statement: definition of traumatic brain injury. Arch Phys Med Rehabil. 2010; 91(11):1637-1640.

2. Corrigan JD, Selassie AW, Orman JA. The epidemiology of traumatic brain injury. J Head Trauma Rehabil. 2010;25(2):72-80.

3. Tagliaferri F, Compagnone C, Korsic M, Servadei F, Kraus J. A systematic review of brain injury epidemiology in Europe. Acta Neurochir (Wien). 2006;148(3):255-268.

4. [No authors listed]. Consensus conference. Rehabilitation of persons with traumatic brain injury. NIH Consensus Development Panel on Rehabilitation of Persons with Traumatic Brain Injury. JAMA. 1999; 282(10):974-983.

5. Kelestimur F. Chronic trauma in sports as a cause of hypopituitarism. Pituitary. 2005;8(3-4):259-262.

6. Tanriverdi F, Unluhizarci K, Coksevim B, Selcuklu A, Casanueva FF, Kelestimur F. Kickboxing sport as a new cause of traumatic brain injury-mediated hypopituitarism. Clin Endocrinol (Oxf). 2007;66(3): 360-366.

7. Tanriverdi F, Unluhizarci K, Kocyigit I, et al. Brief communication: pituitary volume and function in competing and retired male boxers. Ann Intern Med. 2008;148(11):827-831.

8. Agha A, Rogers B, Sherlock M, et al. Anterior pituitary dysfunction in survivors of traumatic brain injury. $J$ Clin Endocrinol Metab. 2004;89(10):4929-4936.

9. Aimaretti G, Ambrosio MR, Di Somma C, et al. Residual pituitary function after brain injury-induced hypopituitarism: a prospective 12-month study. J Clin Endocrinol Metab. 2005;90(11):6085-6092.

10. Benvenga S, Campenni A, Ruggeri RM, Trimarchi F. Clinical review 113: hypopituitarism secondary to head trauma. J Clin Endocrinol Metab. 2000;85(4):1353-1361.

11. Casanueva FF, Leal A, Koltowska-Haggstrom M, Jonsson P, Goth MI. Traumatic brain injury as a relevant cause of growth hormone deficiency in adults: a KIMS-based study. Arch Phys Med Rehabil. 2005; 86(3):463-468.

12. Kelly DF, Gonzalo IT, Cohan P, Berman N, Swerdloff R, Wang C. Hypopituitarism following traumatic brain injury and aneurysmal subarachnoid hemorrhage: a preliminary report. $J$ Neurosurg. 2000;93(5): $743-752$.

13. Leal-Cerro A, Flores JM, Rincon M, et al. Prevalence of hypopituitarism and growth hormone deficiency in adults long-term after severe traumatic brain injury. Clin Endocrinol (Oxf). 2005;62(5):525-532.

14. Popovic V, Pekic S, Pavlovic D, et al. Hypopituitarism as a consequence of traumatic brain injury (TBI) and its possible relation with cognitive disabilities and mental distress. J Endocrinol Invest. 2004; 27(11):1048-1054.

15. Schneider HJ, Schneider M, Saller B, et al. Prevalence of anterior pituitary insufficiency 3 and 12 months after traumatic brain injury. Eur J Endocrinol. 2006;154(2):259-265.

16. Tanriverdi F, Senyurek H, Unluhizarci K, Selcuklu A, Casanueva FF, Kelestimur F. High risk of hypopituitarism after traumatic brain injury: a prospective investigation of anterior pituitary function in the acute phase and 12 months after trauma. J Clin Endocrinol Metab. 2006;91(6): 2105-2111.

17. Tanriverdi F, Ulutabanca H, Unluhizarci K, Selcuklu A, Casanueva FF, Kelestimur $\mathrm{F}$. Three years prospective investigation of anterior pituitary function after traumatic brain injury: a pilot study. Clin Endocrinol (Oxf). 2008;68(4):573-579. 
18. Tanriverdi F, De Bellis A, Ulutabanca $H$, et al. A five year prospective investigation of anterior pituitary function after traumatic brain injury: is hypopituitarism long-term after head trauma associated with autoimmunity? J Neurotrauma. 2013;30(16):1426-1433.

19. Cryan E. [Pituitary damage due to skull base fracture]. Dtsch Med Wochenschr. 1918;44:1261. German.

20. Kokshoorn NE, Wassenaar MJ, Biermasz NR, et al. Hypopituitarism following traumatic brain injury: prevalence is affected by the use of different dynamic tests and different normal values. Eur J Endocrinol. 2010;162(1):11-18.

21. Teasdale G, Jennett B. Assessment of coma and impaired consciousness. A practical scale. Lancet. 1974;2(7872):81-84.

22. Schneider HJ, Kreitschmann-Andermahr I, Ghigo E, Stalla GK, Agha A. Hypothalamopituitary dysfunction following traumatic brain injury and aneurysmal subarachnoid hemorrhage: a systematic review. JAMA. 2007;298(12):1429-1438.

23. Kopczak A, Kilimann I, von Rosen F, et al. Screening for hypopituitarism in 509 patients with traumatic brain injury or subarachnoid hemorrhage. J Neurotrauma. 2014;31(1):99-107.

24. Lauzier F, Turgeon AF, Boutin A, et al. Clinical outcomes, predictors, and prevalence of anterior pituitary disorders following traumatic brain injury: a systematic review. Crit Care Med. 2014;42(3):712-721.

25. van der Eerden AW, Twickler MT, Sweep FC, et al. Should anterior pituitary function be tested during follow-up of all patients presenting at the emergency department because of traumatic brain injury? Eur $J$ Endocrinol. 2010;162(1):19-28.

26. Kleindienst A, Brabant G, Bock C, Maser-Gluth C, Buchfelder M. Neuroendocrine function following traumatic brain injury and subsequent intensive care treatment: a prospective longitudinal evaluation. $J \mathrm{Neu}$ rotrauma. 2009;26(9):1435-1446.

27. Ghigo E, Masel B, Aimaretti G, et al. Consensus guidelines on screening for hypopituitarism following traumatic brain injury. Brain Inj. 2005;19(9):711-724.

28. Aimaretti G, Ghigo E. Should every patient with traumatic brain injury be referred to an endocrinologist? Nat Clin Pract Endocrinol Metab. 2007;3(4):318-319.

29. Behan LA, Phillips J, Thompson CJ, Agha A. Neuroendocrine disorders after traumatic brain injury. J Neurol Neurosurg Psychiatry. 2008; 79(7):753-759.

30. Corneli G, Ghigo E, Aimaretti G. Managing patients with hypopituitarism after traumatic brain injury. Curr Opin Endocrinol Diabetes Obes. 2007;14(4):301-305.

31. Gasco V, Prodam F, Pagano L, et al. Hypopituitarism following brain injury: when does it occur and how best to test? Pituitary. 2012;15(1): 20-24.

32. Glynn N, Agha A. Which patient requires neuroendocrine assessment following traumatic brain injury, when and how? Clin Endocrinol (Oxf). 2013;78(1):17-20.

33. Tanriverdi F, Unluhizarci K, Kelestimur F. Pituitary function in subjects with mild traumatic brain injury: a review of literature and proposal of a screening strategy. Pituitary. 2010;13(2):146-153.

34. Luoto TM, Tenovuo O, Kataja A, Brander A, Ohman J, Iverson GL. Who gets recruited in mild traumatic brain injury research? J Neurotrauma. 2013;30(1):11-16.

35. Kraus JF, Chu LD. Epidemiology. In: Silver JM, McAllister TW, Yudofsky SC, editors. Textbook of Traumatic Brain Injury. Washington, DC, USA: American Psychiatric Publishing Inc; 2005.

36. Borg J, Holm L, Peloso PM, et al. Non-surgical intervention and cost for mild traumatic brain injury: results of the WHO Collaborating Centre Task Force on Mild Traumatic Brain Injury. J Rehabil Med. 2004;43 Suppl:76-83.

37. French BN, Dublin AB. The value of computerized tomography in the management of 1,000 consecutive head injuries. Surg Neurol. 1977; 7(4):171-183.
38. Iverson GL, Lovell MR, Smith S, Franzen MD. Prevalence of abnormal CT-scans following mild head injury. Brain Inj. 2000;14(12): $1057-1061$

39. Williams DH, Levin HS, Eisenberg HM. Mild head injury classification. Neurosurgery. 1990;27(3):422-428.

40. Lange RT, Iverson GL, Franzen MD. Neuropsychological functioning following complicated vs uncomplicated mild traumatic brain injury. Brain Inj. 2009;23(2):83-91.

41. Tanriverdi F, Unluhizarci K, Kelestimur F, Sherlock M, Cooper MS. Endocrinology of acute brain injury. In: Godoy DA, editor. Intensive Care in Neurology and Neurosurgery. Torino, Italy: SEEd Medical Publishers; 2013.

42. Tanriverdi F, Ulutabanca H, Unluhizarci K, Selcuklu A, Casanueva FF, Kelestimur F. Pituitary functions in the acute phase of traumatic brain injury: are they related to severity of the injury or mortality? Brain Inj. 2007;21(4):433-439.

43. Agha A, Phillips J, O’Kelly P, Tormey W, Thompson CJ. The natural history of post-traumatic hypopituitarism: implications for assessment and treatment. Am J Med. 2005;118(12):1416.

44. Klose M, Juul A, Struck J, Morgenthaler NG, Kosteljanetz M, FeldtRasmussen U. Acute and long-term pituitary insufficiency in traumatic brain injury: a prospective single-centre study. Clin Endocrinol (Oxf). 2007;67(4):598-606.

45. Krahulik D, Zapletalova J, Frysak Z, Vaverka M. Dysfunction of hypothalamic-hypophysial axis after traumatic brain injury in adults. J Neurosurg. 2010;113(3):581-584.

46. Cohan P, Wang C, McArthur DL, et al. Acute secondary adrenal insufficiency after traumatic brain injury: a prospective study. Crit Care Med. 2005;33(10):2358-2366.

47. Cooper MS, Stewart PM. Adrenal insufficiency in critical illness. J Intensive Care Med. 2007;22(6):348-362.

48. Hannon MJ, Crowley RK, Behan LA, et al. Acute glucocorticoid deficiency and diabetes insipidus are common after acute traumatic brain injury and predict mortality. J Clin Endocrinol Metab. 2013;98(8):3229-3237.

49. Tanriverdi F. Hypopituitarism due to head trauma: new insights into an old story. Erciyes Med J. 2013;35(4):187-188.

50. Della CF, Mancini A, Valle D, et al. Provocative hypothalamopituitary axis tests in severe head injury: correlations with severity and prognosis. Crit Care Med. 1998;26(8):1419-1426.

51. Hackl JM, Gottardis M, Wieser C, et al. Endocrine abnormalities in severe traumatic brain injury - a cue to prognosis in severe craniocerebral trauma? Intensive Care Med. 1991;17(1):25-29.

52. Agha A, Rogers B, Mylotte D, et al. Neuroendocrine dysfunction in the acute phase of traumatic brain injury. Clin Endocrinol (Oxf). 2004; 60(5):584-591.

53. Cernak I, Savic VJ, Lazarov A, Joksimovic M, Markovic S. Neuroendocrine responses following graded traumatic brain injury in male adults. Brain Inj. 1999;13(12):1005-1015.

54. Schmidt IL, Lahner H, Mann K, Petersenn S. Diagnosis of adrenal insufficiency: Evaluation of the corticotropin-releasing hormone test and basal serum cortisol in comparison to the insulin tolerance test in patients with hypothalamic-pituitary-adrenal disease. J Clin Endocrinol Metab. 2003;88(9):4193-4198.

55. Tanriverdi F, Agha A, Aimaretti G, et al. Manifesto for the current understanding and management of traumatic brain injury-induced hypopituitarism. J Endocrinol Invest. 2011;34(7):541-543.

56. Tanriverdi F, Schneider HJ, Aimaretti G, Nasel BE, Casanueva FF, Kelestimur F. Pituitary dysfunction after traumatic brain injury: a clinical and pathophysiological approach. Endocr Rev. 2015;36(3): 305-402.

57. Sundaram NK, Geer EB, Greenwald BD. The impact of traumatic brain injury on pituitary function. Endocrinol Metab Clin N Am. 2013;42(3): $565-583$. 


\section{Publish your work in this journal}

Neuropsychiatric Disease and Treatment is an international, peerreviewed journal of clinical therapeutics and pharmacology focusing on concise rapid reporting of clinical or pre-clinical studies on a range of neuropsychiatric and neurological disorders. This journal is indexed on PubMed Central, the 'PsycINFO' database and CAS, and is the official journal of The International Neuropsychiatric Association (INA). The manuscript management system is completely online and includes a very quick and fair peer-review system, which is all easy to use. Visit http://www.dovepress.com/testimonials.php to read real quotes from published authors.

\footnotetext{
Submit your manuscript here: http://www.dovepress.com/neuropsychiatric-disease-and-treatment-journal
} 